\title{
Hydroxyurea-Induced Partial Mushroom Body Ablation Does Not Affect Acquisition and Retention of Olfactory Differential Conditioning in Honeybees
}

\author{
Dagmar Malun, ${ }^{1}$ Martin Giurfa, ${ }^{2}$ C. Giovanni Galizia, ${ }^{1}$ Niels Plath, ${ }^{3}$ Robert Brandt, ${ }^{1}$ \\ Bertram Gerber, ${ }^{4}$ Beate Eisermann ${ }^{1}$ \\ ${ }^{1}$ Neurobiologie, Institute für Biologie, Freie Universität Berlin, Königin-Luise-Str. 28-30, 14195 Berlin, \\ Germany \\ ${ }^{2}$ Laboratoire de Cognition Animale, Université Paul Sabatier-Toulouse III, 118 Route de Narbonne, \\ 31062 Toulouse cedex 4, France \\ ${ }^{3}$ Zentrum für Molekulare Neurobiologie, Universität Hamburg, Falkenried 94, 20251 Hamburg, \\ Germany \\ ${ }^{4}$ Institut für Genetik und Neurobiologie, Universität Würzburg, Biozentrum Am Hubland, 97074 \\ Würzburg, Germany \\ Received 28 February 2002; accepted 24 June 2002
}

\begin{abstract}
The mushroom bodies (MBs), a paired structure in the insect brain, play a major role in storing and retrieving olfactory memories. We tested whether olfactory learning and odor processing is impaired in honeybees in which MB subunits were partially ablated. Using hydroxyurea (HU) to selectively kill proliferating cells, we created honeybees with varying degrees of MB lesions. Three-dimensional reconstructions of brains were generated to analyze the druginduced morphological changes. These reconstructions show that, with few exceptions, only the MBs were affected by the drug, while other brain areas remained morphometrically intact. Typically, lesions affected only the MB in one hemisphere of the brain. To preclude HU-induced physiologic deficits in the antennal lobe (AL) affecting olfactory learning, we measured the re-
\end{abstract}

sponses to odors in the $\mathrm{AL}$ using an in vivo calcium imaging approach. The response patterns did not differ between the $\mathrm{AL}$ of intact versus ablated brain sides within respective specimens. We, therefore, carried out side-specific classical discriminative olfactory conditioning of the proboscis extension reflex (PER) with control bees and with HU-treated bees with or without MB ablations. All experimental groups learned equally to discriminate and respond to a rewarded $(\mathrm{CS}+)$ but not to an unrewarded ( $\mathrm{CS}-$ ) conditioned stimulus during acquisition and retention tests. Thus, our results indicate that partial MB lesions do not affect this form of elemental olfactory learning. (c) 2002 Wiley Periodicals, Inc. J Neurobiol 53: 343-360, 2002

Keywords: insect mushroom body; chemical ablation; olfaction; learning and memory; calcium imaging
Correspondence to: D. Malun (malun@zedat.fu-berlin.de). Contract grant sponsor: DFG; contract grant number: SFB 515 (to D.M. and M.G.)

Contract grant sponsor: Fondation pour la Recherche Medicale, France (to M.G.).

Contract grant sponsor: BMBF; contract grant number: 0310961 (to R.B.)

Contract grant sponsor: Human Frontier Science Program (to M.G. and G.C.G.).

Contract grant sponsor: Volkswagen Stiftung; contract grant number: VW 1/75 399 (to G.C.G.)
Contract grant sponsor: Volkswagen Stiftung; contract grant number: VW I/ 76240 (to B.G.).

Contract grant sponsor: SFB; contract grant number: 554 (to B.G.).

(C) 2002 Wiley Periodicals, Inc.

DOI 10.1002/neu.10119 


\section{INTRODUCTION}

Understanding the functional link between the central nervous system and learning capabilities is one of the major challenges of modern neuroscience. One possible approach to studying this problem is the use of selective lesions affecting defined areas of the brain that are thought to be involved in specific learning and memory processes. Applying this procedure to the vertebrate brain has revealed specific networks underlying different forms of learning and memory (Anagnostaras et al., 1999; Riedel et al., 1999; Sakai and Yamamoto, 2001). Research on invertebrates yielded fundamental knowledge about the cellular and molecular principles governing learning and memory (Kandel and Schwartz, 1982; Davis, 1996; Heisenberg, 1998; Milner et al., 1998; Dubnau and Tully, 2001; Sutton et al., 2001; Menzel, 2001). Among invertebrates, the honeybee Apis mellifera is a useful model for examining the relationship between behavioral and neuronal plasticity (Menzel and Müller, 1996; Hammer, 1997; Menzel 1999, 2001). The honeybee brain has a volume of ca. $1 \mathrm{~mm}^{3}$ and consists of approximately 960,000 neurons. Despite this small size, the honeybee displays a rich behavioral repertoire and impressive cognition-like capabilities (Menzel and Giurfa, 2001). The neural circuits potentially underlying some of these capabilities have been studied extensively.

In the bee brain, cognition-like abilities and multimodal integration have been attributed to central, paired, and bilaterally symmetric structures called the mushroom bodies (MB; Menzel et al., 1994). Each MB has approximately 170,000 tightly packed neurons, the Kenyon cells, and consists of two subunits - a lateral and a median one. The dendritic input region to each subunit is the calyx. Each MB subunit has its own separate calyx, which is subdivided into three compartments- the lip, the collar, and the basal ring. Each compartment receives a specific sensory input (lip: olfactory; collar: visual; basal ring: olfactory, visual and mechanosensory; Mobbs, 1984; Abel et al., 2001). The axonal output projects into the $\alpha$ and $\beta$-lobes, which are fused components of both median and lateral MB subunits. In contrast to the compartmentalized sensory input to the calyx, $\mathrm{MB}$ output (Mauelshagen, 1993; Rybak and Menzel, 1993) has multimodal response characteristics (Rybak and Menzel, 1998), suggesting an integrative role for the honeybee MBs.

Despite their multimodal nature, the honeybee MBs have been studied primarily for their function in olfactory memory (for review, see Menzel, 1999,
2001; Menzel and Giurfa, 2001). Such studies used the paradigm of olfactory conditioning of the proboscis extension reflex (PER). In this paradigm, harnessed honeybees are conditioned to olfactory stimuli associated with a sucrose solution reward (Takeda, 1961; Bitterman et al., 1983). When the antennae of a hungry bee are touched with sucrose solution, the animal reflexively extends its proboscis to reach out to and feed on the sucrose. Odors applied to the antennae do not release such a reflex in naive animals. If, however, an odor had been presented immediately before sucrose solution (forward pairing), an association is formed, which enables the odor to release the PER in a following test. This effect is clearly associative and involves classical conditioning (Bitterman et al., 1983). Differential conditioning, i.e., learning in addition that a different odor is no predictor for reward, is also possible. The role of different neuropils in the olfactory pathway (e.g., $\mathrm{AL}, \mathrm{MB}$, lateral protocerebrum) in olfactory learning and memory formation has been studied in the past using reversible local blockades of neural activity, local injections of the putative transmitter in the reward pathway, and imaging of learning-related changes in odor-induced activity patterns (for reviews, see: Menzel et al., 1994; Menzel and Müller, 1996; Galizia and Menzel, 2001; Menzel, 2001). Results of all these approaches indicate a temporally and spatially distributed memory trace, including the AL's capability for forming an associative olfactory memory (Hammer and Menzel, 1998; Faber et al., 1999; Menzel, 1999).

Recently, a method has been developed for studying the functional role of honeybee MBs (Malun, 1998). Such a method, first established for the fruit fly Drosophila melanogaster (deBelle and Heisenberg, 1994), induces lesions in specific regions of the brain, which then can be studied for their involvement in learning and memory. It makes use of the DNA synthesis inhibitor hydroxyurea (HU) to kill dividing MB neuroblasts and to achieve chemical ablation of MB. In the case of the honeybee, partial lesions affecting one or two MB subunits are obtained (Malun et al., 2002). This is achieved by feeding the drug to early first-instar larvae and thus killing MB neuroblasts. In the bee, Kenyon cells of each MB subunit are generated in their respective proliferation centers from the first larval stage onwards (Malun, 1998, Farris et al., 1999). Each proliferation center and thus each MB subunit is thought to derive from a very small number of origin MB neuroblasts (Malun, 1998). To avoid lesions of other than the MB neuroblasts, HU treatment is carried out on early first instar larvae, resulting in preferential ablation of one or both median MB subunits while the lateral subunits remain. This most 
likely indicates that the median proliferation centers precede the lateral ones in development. MB lesions obtained in this way can be asymmetric, and thus circumscribed to one side of the brain (Malun, 1998). Such lesions do not affect side-specific, associative tactile antennal learning in honeybees, i.e., operant scanning and learning of an object within the range of an antenna (Scheiner et al., 2001). This result may be attributed to the specific sensory modality tested (mechanosensory), or may be a general effect associated with the kind of learning task (operant and elemental) tested.

In the present work, we used $\mathrm{HU}$ ablation to further study the involvement of MBs in another elemental learning task, classical olfactory conditioning of the PER. We used side-specific olfactory conditioning to determine whether MB ablations cause deficiencies in olfactory learning and memory. To make sure that an absence of the MB leaves the basic physiology of the AL undistorted, we performed in vivo calcium imaging of the AL (Joerges et al., 1997; Galizia and Menzel, 2001) of unilaterally MB-ablated bees. In a quite exhaustive previous study it was shown that the volume of the AL neuropil of HU-treated animals (with unilateral, bilateral, or without MB ablation) was not different from that of control animals, indicating that the AL itself was not affected by the drug (Malun et al., 2002). Still, this volumetric study needed a physiologic complement, which is now provided. As we compare AL physiology between MBablated and MB-intact hemispheres of the same individual, our current imaging approach can be used to determine whether MB lesions may retrogradely affect AL physiology.

\section{MATERIALS AND METHODS}

\section{General}

We treated early larval stages of honeybees with $\mathrm{HU}$ to cause MB ablations. Animals were then subjected to either behavioral or imaging experiments. These experiments were designed as a double-blind test with no knowledge of whether bees had been treated with HU or not. The person doing the experiments with HU-treated bees was ignorant concerning the occurrence or degree of MB lesions, as these lesions are not visible from the outside. Subsequent to the learning or imaging experiments, the MB status was determined by another person who did not know the results of the learning or imaging experiments; finally, 3D reconstructions were carried out.

\section{Hydroxyurea Treatment}

Treatment with HU was performed as described previously (Malun, 1998; Scheiner et al., 2001; Malun et al., 2002): 0.5 $\mathrm{mg} / \mathrm{mL}$ of a HU/royal jelly: $\mathrm{H}_{2} \mathrm{O}$ 1:1 solution was fed for 3 to $4 \mathrm{~h}$ to early first-instar honeybee larvae (Apis mellifera) placed in microwells during treatment. Extending the time of treatment caused considerable larval and pupal lethality. Control animals were treated in the same way, but HU was omitted. The microwells were kept in a humid chamber at $33^{\circ} \mathrm{C}$. Thereafter larvae were rinsed with distilled $\mathrm{H}_{2} \mathrm{O}$ and returned to the hive for further development. Pupae were removed from the hive on the day when hatching was expected and kept in small cages until hatching. Adult bees were then kept either in small groups of about 10 animals placed in small grated cages between the combs of the hive or in little colonies of about 50 animals contained in small boxes with food (Neopoll, Seip, Germany). The boxes were kept in an incubator for 5 to 7 days at $33^{\circ} \mathrm{C}$ and $60 \%$ humidity.

\section{Histological Examination}

Whole-Mount Dissections and Staining. Five- to 7-dayold honeybee workers were immobilized on ice and decapitated. Head capsules were opened from the anterior in phosphate-buffered saline (PBS, $137 \mathrm{mM} \mathrm{NaCl}, 2.7 \mathrm{~m} M$ $\mathrm{KCl}, 10.1 \mathrm{~m} M \mathrm{Na}_{2} \mathrm{HPO}_{4}, 1.8 \mathrm{~m} M \mathrm{KH}_{2} \mathrm{PO}_{4}$ ). Antennae, tracheae, and glands were removed and the mouthparts cut off. To reduce tissue distortion heads were then prefixated for approximately $30 \mathrm{~min}$ in $4 \%$ paraformaldehyde. Subsequently, brains were removed from the head capsule, carefully freed from tracheal and glandular tissue, and thoroughly checked for MB ablation. To analyze HU-induced MB lesions in detail, neuropil areas of the brains were stained with synapsin antibodies. The same procedure was also carried out for the brains of control animals. Specimen were fixated in $4 \%$ paraformaldehyde for at least another $1.5 \mathrm{~h}$. Brains were then rinsed six times, $1 \mathrm{~h}$ each, in PBS $+1 \%$ Triton X-100 (PBST), blocked with $10 \%$ normal goat serum (NGS, Sigma) in PBST (NGS-PBST) for $1 \mathrm{~h}$. They were subsequently incubated for $60 \mathrm{~h}$ in the primary antibodies nc46 and SYNORF1, each diluted 1:30 in NGSPBST. Both primary antibodies were obtained from a screen of Drosophila synapse proteins (Hofbauer, 1989) and were generously provided by Dr. E. Buchner, University of Würzburg, Germany, and Dr. A. Hofbauer, University of Regensburg, Germany. Preparations were rinsed again six times, $1 \mathrm{~h}$ each, in PBST and were then incubated for $36 \mathrm{~h}$ with a Cy3-conjugated mouse-antirabbit secondary antibody (Jackson ImmunoResearch; dilution: 1:200 in NGSPBST). After rinsing in PBS for $1 \mathrm{~h}$, brains were dehydrated in an increasing ethanol series $(50,70,90,99 \%, 2 \times 100 \%$, $10 \mathrm{~min}$ each), cleared in methylsalicylate, and mounted as whole mounts in Permount (Sigma), in double-sided custom slides.

Confocal Microscopy. Whole mounts were imaged with a confocal laser-scanning microscope (Leica TCS 4D) using a 
Leica HC PL APO $10 \times / 0.4$ air objective. The chromophore was excited with the $568 \mathrm{~nm}$ line of the ArKr laser, detected using a LP590 long-pass filter, and digitized using eight-bit resolution. Due to the size of the dissected and embedded brain, which extends laterally about $2.5 \times 1.6 \mathrm{~mm}$ and ca. $0.8 \mathrm{~mm}$ axially, the entire brain cannot be imaged in a single scan with the desired axial resolution. Therefore, we used multiple image-stack acquisition (3D-MISA; Zuschratter et al., 1998). To do so, the entire brain was scanned in $2 \times 3$ single scans, each using $512 \times 512$ pixels laterally and between 80 and 120 sections axially. Subsequently, stacks were combined using custom software or a custom script running in the Amira 3D scientific visualization and data analysis package (http://www.amiravis.com). Due to the air objective, there is a shortening in $\mathrm{z}$-direction that was accounted for by a linear scaling factor of 1.6 in the zdirection (Bucher et al., 2000).

Image Processing and Reconstruction. All image processing was done with the Amira package (see above) on a Unix Workstation (SGI O2, R5000, 832 MB Ram) or on a PC (Pentium II 350Mhz, $256 \mathrm{MB}$ main memory running under Linux). First, to increase display speed and to save computer memory, image stacks were resampled laterally to half of the original dimensions so that the effective sampling in xy amounted to $3.8 \mu \mathrm{m}$. In most cases no further image processing was necessary except for adjustment of the gray value mapping. In a few cases unsharp masking filters were applied to enhance contours. Subsequently, stacks were loaded into the Amira segmentation editor and the neuropil areas of interest were traced manually on each slice (Rohlfing et al., 2001). We distinguished 11 major compartments, 8 of which are bilaterally symmetric on either brain hemisphere. The paired structures were the medulla (ME), the lobula (LO), the antennal lobe (AL), the mushroom body (MB) consisting of the peduncle, the $\alpha$ - and $\beta$-lobes, and the calyces. The MB calyces of the control animal shown in Figure 1 were subdivided into their three subcompartments (lip, collar, and basal ring). The unpaired structures were the central body (CB) with its upper and lower division and the protocerebral lobes (PL) including the suboesophageal ganglion (SOG).

Optical Imaging of Antennal Lobe Activity. Because we wanted to study the involvement of MBs in elementary olfactory conditioning, it was important to verify that HUinduced MB lesions did not already distort olfactory physiology at the peripheral stage. We therefore analyzed olfactory processing in the $\mathrm{AL}$, which is the primary olfactory neuropil in the bee brain, receiving the input from olfactory receptors on the antennae. Each AL consists of approximately 160 glomeruli. Odor stimulation evokes specific spatial patterns of glomerular activation, which can be imaged using calcium-sensitive fluorescent dyes (Joerges et al., 1997; Sachse et al., 1999; Galizia and Menzel, 2001). As these patterns are bilaterally symmetric (Galizia et al., 1998), we aimed at comparing glomerular activity patterns of animals with unilateral MB lesions; thus, within a given

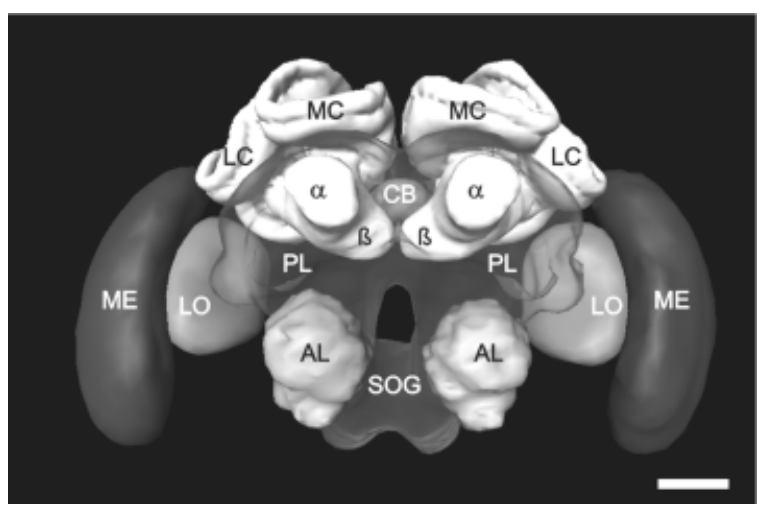

Figure $13 \mathrm{D}$ reconstruction of the brain of a control honeybee as seen from the front. Each MB consists of a median and a lateral subunit. $\alpha, \alpha$-lobe; AL, antennal lobe; $\beta, \beta$-lobe; $\mathrm{CB}$, central body; LC, calyx of the lateral MB subunit; LO, lobula; MC, calyx of the median MB subunit; ME, medulla; PL, protocerebral lobe; SOG, suboesophageal ganglion. Bar $=200 \mu \mathrm{m}$. The figure was generously provided by Nicola Stollhoff.

specimen we were able to test the effects of MB ablation on AL function.

Bees were chilled and fixed in a Plexiglas stage. The ALs were exposed, and the brain superfused with $50 \mu M$ Calcium-Green-2 AM (Molecular Probes, Leiden) dissolved in bee Ringer $(130 \mathrm{~m} M \mathrm{NaCl}, 6 \mathrm{mM} \mathrm{KCl}, 4 \mathrm{mM}$ $\mathrm{MgCl}_{2}, 5 \mathrm{~m} M \mathrm{CaCl}_{2}, 160 \mathrm{~m} M$ sucrose, $25 \mathrm{~m} M$ glucose, 10 $\mathrm{m} M$ HEPES, $\mathrm{pH}$ 6.7, $500 \mathrm{mOsmol}$; all chemicals from Sigma, Deisenhofen, Germany). After $1 \mathrm{~h}$ of staining, excess dye was rinsed, and the bee was observed under a microscope (Olympus BX 50) using a water-immersion objective (20×, NA 0.5) and imaged (imaging system from Till Photonics, Martinsried, Germany). Ringer was regularly replaced, but no constant perfusion was applied. The excitation light was $475 \mathrm{~nm}$, dichroic DCLP 500, emission filter was LP515. Images were taken for $20 \mathrm{~s}$, at a rate of 5 frames/s, and single-frame exposure time of $50 \mathrm{~ms}$. Odors were applied with computer-controlled solenoid valves at frame 25; stimulus length was $1 \mathrm{~s}$. Intertrial interval was at least $1 \mathrm{~min}$. Images were binned on chip to reach an effective pixel size of $2.4 \mu \mathrm{m}^{2}$. In each measurement, only the left or the right AL could be seen. In most measurements, body side was changed every two odors. In a subset, all odors were first measured on one side, and then on the other. A computer-controlled microstage (Luigs \& Neumann, Ratingen, Germany) was used to focus and center the AL, and to precisely reposition the preparation when sides were repeatedly changed. We tested 10 odors: isoamylacetate, citral, geraniol, linalool, orange oil, 1-hexanol, 1-octanol, 1-nonanol, octanal, and octanone. In all cases, $4 \mu \mathrm{L}$ of the pure substance were placed on a round filter paper (diameter $13 \mathrm{~mm}$ ) and inserted into a glass Pasteur pipette. An untreated filter paper was used as control. The olfactory stimulus was injected into a constant air stream, leading to a diluted stimulus at the bee's antennae. Each odor was pre- 
sented at least twice on each body side, to compare acrosstrial variability within one AL with the bilateral variability (Galizia et al., 1998).

\section{Anatomical Analysis}

Because in functional measurements the anatomical borders of the glomeruli were not visible, it was necessary to stain them with a different dye. After functional imaging, brains were treated for 45 min with the hydrophobic dye RH795 (Molecular Probes) dissolved in protease (P5459 in most animals, P5147 in some, both from Sigma) (1 mg dye was first dissolved in $1 \mathrm{~mL}$ ethanol; $4 \mu \mathrm{L}$ of this stock solution were then mixed with $500 \mu \mathrm{L}$ protease). This treatment labeled individual glomeruli clearly. For each AL, a series of 21 virtual z-slices centered on the functional imaging focal plane were taken (interslice distance: $5 \mu \mathrm{m}$ ). Excitation light was $530 \mathrm{~nm}$, dichroic $580 \mathrm{~nm}$, emission 615 $\pm 22.5 \mathrm{~nm}$. Then brains were fixed in $4 \%$ formalin and removed from the head capsule to assess MB status.

\section{Data Analysis}

Signals were calculated as relative changes in fluorescence intensity $(\Delta \mathrm{F} / \mathrm{F})$ as previously described (Galizia et al., 2000). Briefly, false-color images were calculated as the activity $1 \mathrm{~s}$ after stimulus onset by averaging three frames $1 \mathrm{~s}$ after stimulus onset, and subtracting three frames right before stimulus onset. For the reader's convenience, images from the right $\mathrm{AL}$ were mirror-flipped to facilitate the comparison between the two sides. In a subset of animals, activity was analyzed on a single-glomerulus basis. We calculated the response intensity of individual glomeruli, which we identified on the basis of their morphologic shape and relative position. This allows to directly compare left and right body sides and different animals without being affected by different views. To this end, individual glomeruli were identified from the RH795 afterstaining by comparing the glomerular shape and size with the digital atlas of the honeybee AL (Galizia et al., 1999a). We then selected a square (corresponding to $34 \times 34 \mu \mathrm{m}$ on the AL) in each glomerulus for each AL, and calculated the time courses for these glomeruli. From these time courses glomerular activity patterns were calculated by averaging three frames $1 \mathrm{~s}$ after stimulus onset, and subtracting three frames right before stimulus onset, yielding data equivalent to the falsecolor coded images, but as a vector over known glomeruli. These vectors were then compared between the two body sides and with the published glomerular odor responses (Galizia et al., 1999b).

\section{Side-Specific Olfactory Conditioning}

HU-treated bees were subjected to an elemental olfactory conditioning task to determine whether a complete set of MBs is required for the acquisition and retrieval of such a task. Bees were differentially conditioned, i.e., they had to learn to respond to a reinforced odor but not a nonreinforced odor.

Honeybees were taken from the small grated cages or the little colony boxes (see above) in the afternoon before each experiment day. They were then placed in small glass vials and cooled on ice until they stopped moving. The bees were then harnessed in small metal tubes such that they could only move their antennae and mouthparts, including the proboscis (Takeda, 1961; Bitterman et al., 1983). To perform side-specific olfactory conditioning we removed one antenna (either the left or the right one) and sealed the wound with dental wax. Animals were assigned randomly to each group (left and right antenna, respectively). Bees were fed with $30 \%$ sucrose solution until satiation and kept overnight in a humid, dark, cool $\left(18^{\circ} \mathrm{C}\right)$ box. The next day, animals were tested for intact reflexes by lightly touching the remaining antenna with a toothpick soaked with sucrose solution without subsequent feeding. Extension of the proboscis beyond a virtual line between the open mandibles was counted as PER (unconditioned response); this same criterion was also applied to conditioned responses (see below). Animals that did not show the reflex $(<5 \%)$ were not used for behavioral experiments.

\section{Unconditioned and Conditioned Stimuli}

The unconditioned stimulus (US) was a $30 \%$ sucrose solution. The conditioned stimuli (CS) were the odorants $\mathrm{Ge}$ raniol (MERCK) and 1-Hexanol (Sigma). They were balanced as CS + (odor followed by sucrose reward) or CS(odor not followed by sucrose reward) in the differential conditioning procedure. Four microliters of pure odorant were applied onto a fresh strip of filter paper. Each paper strip was then inserted into a plastic syringe. In each trial, a scented airflow was directed towards the remaining antenna by slowly pressing the syringe from a distance of approximately $5 \mathrm{~cm}$. An air-extraction system behind the bee removed odor-laden air from the surroundings. Such manual odorant delivery is a reliable and standard procedure for simple behavioral experiments (Bitterman et al., 1983).

\section{Acquisition and Retention}

Acquisition consisted of four $\mathrm{CS}+$ and four $\mathrm{CS}-$ trials. Each acquisition trial lasted $60 \mathrm{~s}$. At the beginning of each trial the subject was placed in front of the syringe for $26 \mathrm{~s}$ to allow familiarization with the trial situation. The CS was then presented for $4 \mathrm{~s}$. During reinforced trials (CS+ trials), the US onset occurred $3 \mathrm{~s}$ after CS onset: the remaining antenna was lightly touched with a toothpick soaked with the sucrose solution; after proboscis extension the bee was allowed to feed for $3 \mathrm{~s}$. Therefore, the interstimulus interval was $3 \mathrm{~s}$ and the overlap between CS and US was $1 \mathrm{~s}$. Nonreinforced trials (CS - trials) consisted of CS presentations without reward. After withdrawal of the US, the bee remained in the same position for $60 \mathrm{~s}$. Animals were then returned to their resting positions. The intertrial interval was $2.5 \mathrm{~min}$. The sequence of $\mathrm{CS}+$ and $\mathrm{CS}-$ during acquisition 
was pseudorandomized for each bee, which means that a maximum of two trials with a CS of the same sign was allowed during the eight CS presentations (four CS + and four $\mathrm{CS}-$ ). The odorant chosen as $\mathrm{CS}+$ for a particular bee was consistently paired with the US. That chosen as the CS - was not associated with US.

Retention consisted of two consecutive tests. In each test the previously reinforced $(\mathrm{CS}+)$ and nonreinforced $(\mathrm{CS}-$ ) odors were presented once in extinction conditions (i.e., no reward was given after odor stimulation). Retention tests were performed after the end of the acquisition phase. One test was performed $1 \mathrm{~h}$ after the last acquisition trial and the other one, 1 day later. The sequence of $\mathrm{CS}+$ and $\mathrm{CS}-$ stimulation was balanced across subjects.

\section{Response Measurement}

We recorded whether, in the case of reinforced trials, a bee extended its proboscis after odor onset (CS) and before presentation of the sucrose solution (US). For nonreinforced trials, we scored a response if the proboscis was extended within $6 \mathrm{~s}$ after CS onset. After completing the experiments, all animals were again checked for proboscis extension reflex. If an animal did not respond, it was discarded $(<5 \%)$. Finally, histologic examination as described above determined the presence or absence of MB lesions.

\section{Experimental Groups}

Our HU treatment procedure resulted in five groups of animals, one control group, which was not HU-treated and four HU-treated groups; due to the nature of the HUinduced effects, these four groups could be determined only a posteriori by histologic examination. The five experimental groups are therefore defined as: (1) controls: treated identically as the HU-treated groups except that HU was omitted from the feeding solution; (2) HU normal: HUtreated animals that did not show any measurable reduction in MB volume; (3) HU ipsilateral: HU-treated animals that had one median MB subunit missing on the side where the antenna was intact; (4) $H U$ contralateral: HU-treated animals that had one median MB subunit missing on the side contralateral to the intact antenna; and (5) HU bilateral: HU-treated animals that had both median MB subunits missing.

\section{Statistics}

We measured the percentage of conditioned responses ( $\%$ $\mathrm{PER})$ in the $\mathrm{CS}+$ and $\mathrm{CS}-$ trials. Repeated measurement analyses of variance (ANOVAs) were used for betweengroup as well as within-group comparisons. Monte Carlo studies have shown that it is permissible to use ANOVA in case of dichotomous data such as those of the PER under certain conditions (Lunney, 1970), which are met by the experiments reported here. Where necessary, NewmanKeuls tests were used to perform post hoc comparisons. The alpha level was set at $5 \%$ for all analyses. Within-groups, we compared response levels to CS + and CS - (main effect odor: overall discriminative response), the course of responses (main effect trial), and the development of discriminative responses over trials (odor $\times$ trial interaction, i.e., the dynamics of $\mathrm{CS}+$ and $\mathrm{CS}-$ responding along trials).

\section{RESULTS}

\section{D Brain Reconstructions of Hydroxyurea-Treated Bees}

Figure 1 shows the 3D model of the brain of a control animal, including the neuropil compartments that were reconstructed from confocal images taken through the honeybee's brain. Figure 2 shows the 3D reconstructions of the brains of HU-treated animals, i.e., (a) HU-normal bees, (b) HU-bees with partial unilateral MB lesion (lacking one median MB subunit), (c) HU-bees with partial bilateral MB lesion (lacking both median MB subunits), (d) HU-bees with a complete unilateral MB lesion (lacking both MB subunits of one brain side), and (e) HU-bees with complete bilateral MB lesion (the complete MB neuropil is gone except for a small group of about 50 Kenyon cells left in one brain side). Table 1 summarizes the number of specimens exhibiting various types and subtypes of MB ablations observed in the current and previous studies (Malun, 1998; Scheiner et al., 2001; Malun et al., 2002). The data indicate that the HU concentration was minimal, close to the lowest threshold, because half $(52.56 \%)$ of the treated animals did not show any MB ablation. The data also show that, as expected from the proliferation pattern of MB neuroblasts (Malun, 1998), most often the median MB subunits were affected. The small percentage of other subtypes of MB ablations was presumably caused by the particular quantity of $\mathrm{HU}$ absorbed by the larvae, a parameter that cannot be controlled by the experimenter.

The brains of HU-normal animals [including the MBs and their subcompartments, as well as all other brain areas, Fig. 2(A)] did not differ in their morphology from those of control animals (Fig. 1). In brains with partial unilateral MB ablation [Fig. 2(B)], the loss of a complete median subunit (including its calyx, peduncle and parts of the $\alpha$ - and $\beta$-lobe) resulted in a concomitant reduction in the size of the $\alpha$ - and $\beta$-lobes. Changes within the MBs became particularly obvious when $3 \mathrm{D}$ reconstructions of the MBs alone were produced and inspected from various views [Fig. $3(\mathrm{~A})-(\mathrm{C})]$. The posterior view of the MBs in Figure 3(B) shows that the median MB subunit was ablated, whereas the lateral calyx remained. The remaining 

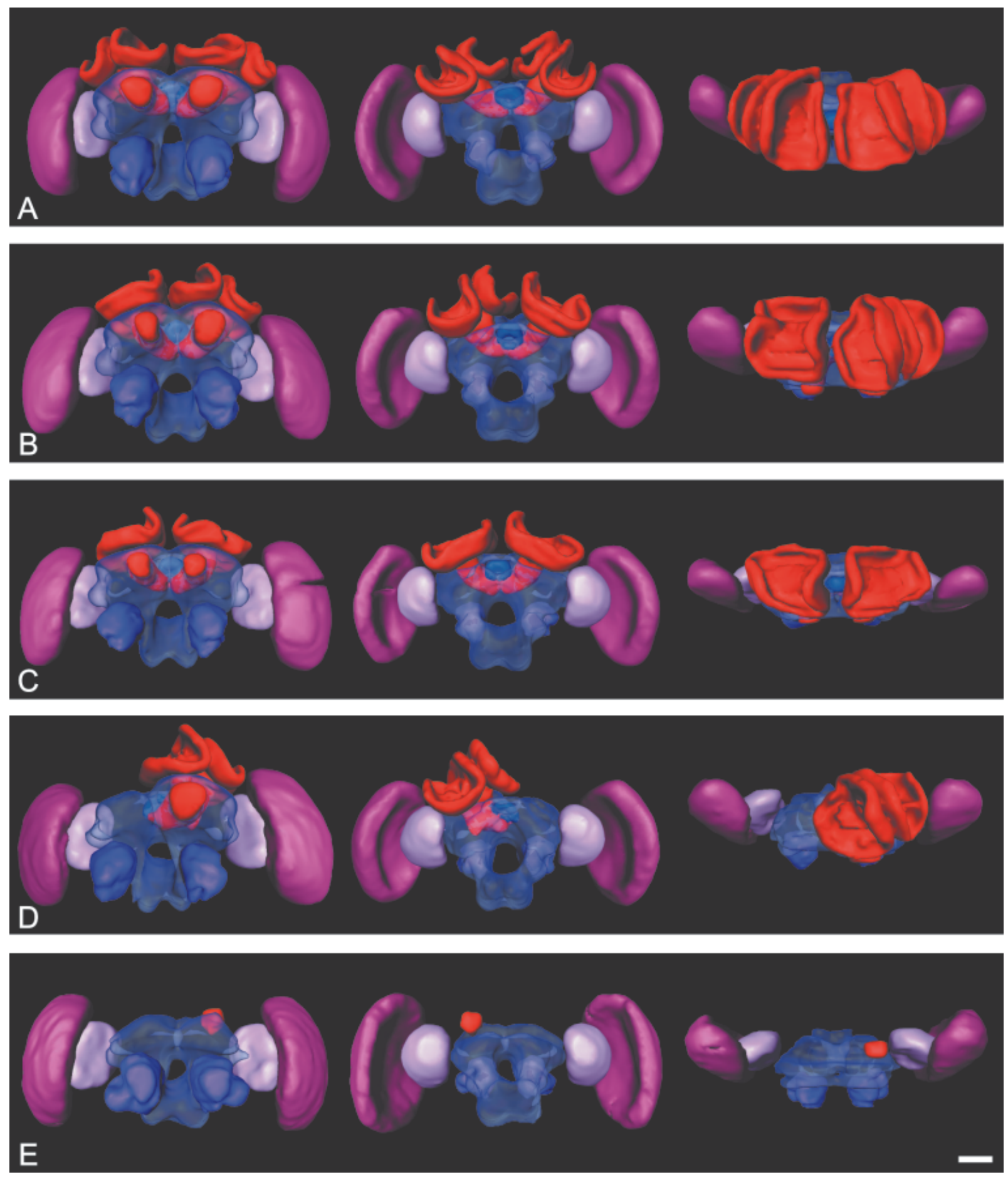

Figure 2 3D reconstructions of brains of HU-treated animals in frontal, posterior, and dorsal views. The MBs are indicated in red. (A) HU-treated brain without MB ablation (HU-normal), all neuropil areas appear normal. (B) Partial unilateral MB ablation, the median MB subunit of the left brain side is absent, whereas the lateral MB subunit remains intact. Neuropil areas other than the MBs appear normal. (C) Partial bilateral MB ablation; both median MB subunits are absent. (D) Complete unilateral MB ablation; the lateral and the median MB subunits of the left brain side are absent. The MB of the opposite brain hemisphere is intact. (E) Complete bilateral ablation; only a small group of Kenyon cells was left in one right brain side, forming a small peduncle, while the calyces and the lobes were absent. The entire protocerebral neuropil appears greatly shrunken because of the complete MB ablation. In this particular brain, the central body was also ablated. Other brain areas such as the optic lobes, the AL, and the central body were not affected by the drug. Bar $=200 \mu \mathrm{m}$. 
Table 1 Effects of $\mathrm{HU}$ on the Honeybee Brain

\begin{tabular}{|c|c|c|c|c|}
\hline \multirow{2}{*}{$\begin{array}{l}\text { HU-Induced Type of } \\
\text { Mushroom Body Ablation }\end{array}$} & \multirow{2}{*}{$\begin{array}{c}\text { Subtype of Mushroom Body } \\
\text { Ablation }\end{array}$} & \multirow{2}{*}{$\begin{array}{c}\text { Ablation Other Than } \\
\text { Mushroom Body } \\
\text { Ablation }\end{array}$} & \multicolumn{2}{|c|}{ Number of Animals } \\
\hline & & & $n=1229$ & $(\%)$ \\
\hline Normal [Fig. 2(A)] & & & 646 & $(52.56 \%)$ \\
\hline $\begin{array}{l}\text { Partial unilateral mushroom } \\
\text { body ablation }\end{array}$ & $\begin{array}{l}\text { Complete ablation of a median } \\
\text { mushroom body subunit } \\
\text { [Fig. } 2(\mathrm{~B})]\end{array}$ & & 404 & $(32.87 \%)$ \\
\hline $\begin{array}{l}\text { Partial unilateral mushroom } \\
\text { body ablation }\end{array}$ & $\begin{array}{l}\text { Reduction of a median mush- } \\
\text { room body subunit }{ }^{\text {a }}\end{array}$ & & 4 & $(0.32 \%)$ \\
\hline $\begin{array}{l}\text { Complete unilateral mushroom } \\
\text { body ablation [Fig. 2(D)] }\end{array}$ & & & 2 & $(0.16 \%)$ \\
\hline $\begin{array}{l}\text { Partial bilateral mushroom } \\
\text { body ablation }\end{array}$ & Normal $\beta$-lobes [Fig. 2(C)] & & 155 & $(12.6 \%)$ \\
\hline $\begin{array}{l}\text { Partial bilateral mushroom } \\
\text { body ablation }\end{array}$ & Fusion of $\beta$-lobes [Fig. 3(D)] & & 4 & $(0.32 \%)$ \\
\hline $\begin{array}{l}\text { Complete unilateral and partial } \\
\text { contra-lateral mushroom } \\
\text { body ablation }^{\mathrm{b}}\end{array}$ & & & 5 & $(0.4 \%)$ \\
\hline $\begin{array}{l}\text { Complete bilateral mushroom } \\
\text { body ablation }\end{array}$ & Complete Kenyon cell ablation & Central body intact ${ }^{\mathrm{b}}$ & 3 & $(0.24 \%)$ \\
\hline $\begin{array}{l}\text { Complete bilateral mushroom } \\
\text { body ablation }\end{array}$ & Complete Kenyon cell ablation & Central body ablated & 1 & $(0.08 \%)$ \\
\hline $\begin{array}{l}\text { Complete bilateral mushroom } \\
\text { body ablation }\end{array}$ & $\begin{array}{l}\text { Small group of Kenyon cells } \\
\text { persists }\end{array}$ & Central body intact & 3 & $(0.24 \%)$ \\
\hline $\begin{array}{l}\text { Complete bilateral mushroom } \\
\text { body ablation }\end{array}$ & $\begin{array}{l}\text { Small group of Kenyon cells } \\
\text { persists }\end{array}$ & $\begin{array}{l}\text { Central body ablated } \\
\text { [Fig. 2(E)] }\end{array}$ & 2 & $(0.16 \%)$ \\
\hline
\end{tabular}

The various types and subtypes of MB ablations are shown, as well as lesions other than MB ablations. The table includes data from Malun (1998), Scheiner et al. (2001), and Malun et al. (2002, this study). Specimens shown in previous publications are indicated by parenthesis. All animals were treated the same way (HU treatment of early first instar larvae, $\mathrm{HU}$ concentration $0.5 \mathrm{mg} / \mathrm{mL}$, duration of treatment 3 to $4 \mathrm{~h}$ ).

${ }^{\text {a }}$ Malun et al., 2002.

${ }^{\mathrm{b}}$ Malun, 1998.

calyx became flatter and larger, and extended towards the midline of the brain. Yet it appeared very similar to the lateral calyx in the intact side regarding its shape, position, and proportion.

The overall morphology of the protocerebrum appeared symmetrical in brains in which both median MB subunits were missing [Figs. 2(C)]. In few of these brains with partial bilateral $\mathrm{MB}$ ablation the $\beta$-lobes were fused in the midline of the brain [Fig. 3(D)]. Obviously, Kenyon cell axons extended across the midline into the contralateral brain side, a finding that was also observed in Drosophila with partial MB ablation after HU treatment (Ito et al., 1997) or in alpha-lobes-absent mutants (Pascual and Préat, 2001). In the bee, a fused $\beta$-lobe was never observed in brains of control animals or animals with unilateral partial MB ablation. Brain areas other than the MBs were not affected by the drug (for a detailed quantification see also Malun et al., 2002). Occasionally, three MB subunits, both median and one lateral MB subunits, were ablated (not shown but listed as complete unilateral and partial contralateral MB ablation in Table 1). Massive asymmetrical MB ablations involving loss of both the median and the lateral $\mathrm{MB}$ subunits of one brain side but not of the other side were observed very rarely [Fig. 2(D), Table 1). On the ablated side of these brains, the protocerebrum appeared drastically reduced in size. Such a reduction became even more obvious in brains with complete bilateral MB ablation [Fig. 2(E)]. In two of these brains (Table 1), only a small group of Kenyon cells (about 50 cells) was left in one brain side, forming a small peduncle while the calyces and the lobes were absent. Complete bilateral MB ablation was sometimes (Table 1) accompanied by the lesion or the ablation of the central body [Fig. 2(E)]. Other brain areas, such as the optic lobes and the AL, were not affected by the drug. Bees exhibiting brains with complete bilateral MB ablation were most often found among animals that died either before or shortly after (within 3 days) adult hatching. Thus, no behavioral experiments could be performed with these animals. Their brains however, were dissected and removed for histologic analysis. 

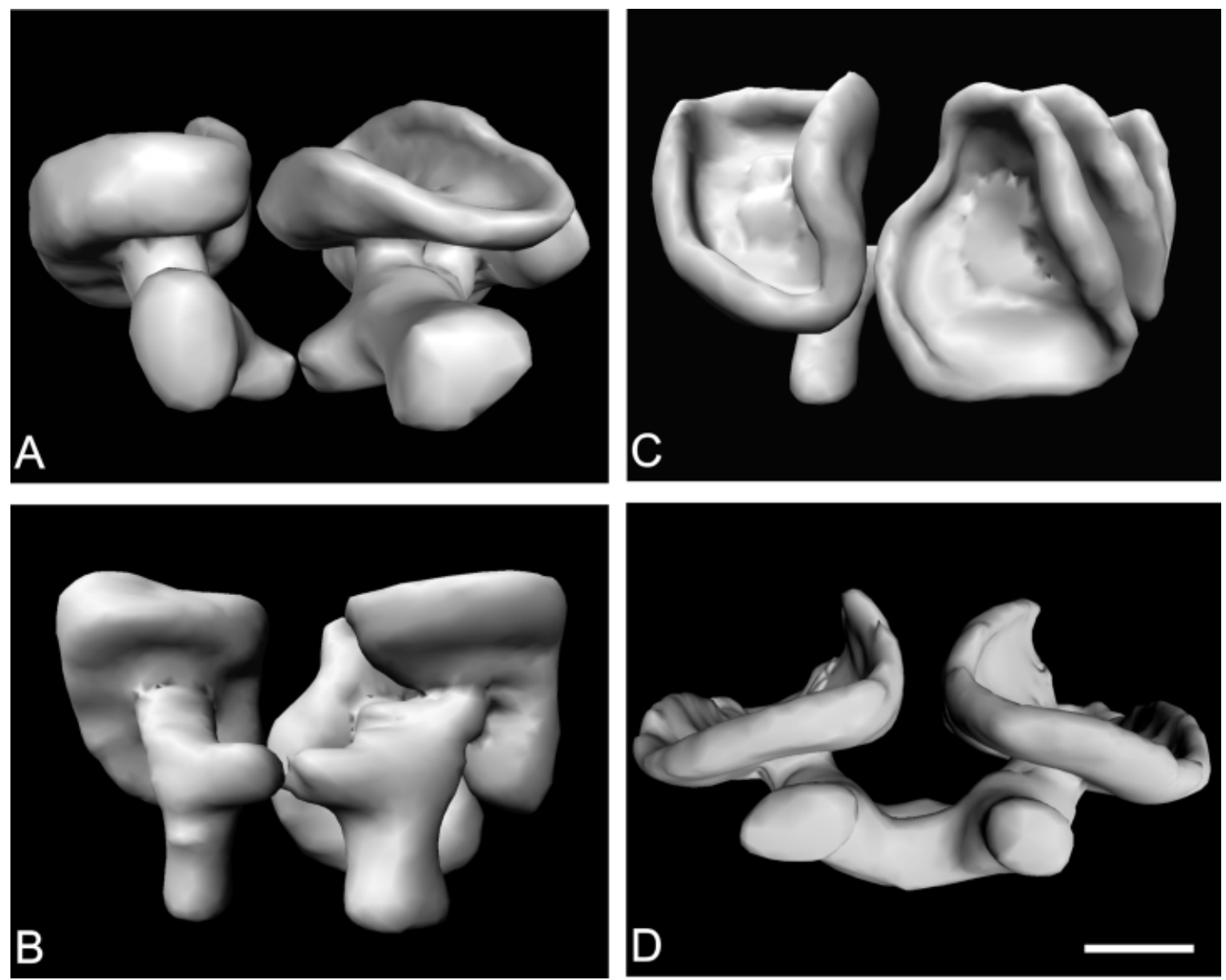

Figure 3 3D reconstructions of MBs with partial unilateral [(A), (B), (C), different views of the same specimen] and partial bilateral (D) MB ablation. (A) Frontal view. The median MB subunit in the left brain side is absent. Thus, only the calyx, the peduncle and the portions of the $\alpha$ - and $\beta$-lobes belonging to the lateral MB subunit remained. Accordingly, the $\alpha$ - and $\beta$-lobes are reduced in size because of the missing portion of the median MB subunit. (B) The ventral view of the brain emphasizes that the lateral MB subunit remains intact because both lateral calyces (of the lesioned and the intact side) look alike regarding their proportion, shape, and position. The median calyx of the intact side has no counterpart in the lesioned side. (C) The dorsal view emphasizes the enlargement of the remaining lateral calyx within the ablated side. (D) Partial bilateral MB ablation as seen from the frontal view. The median MB subunits in both brain sides are ablated. The $\beta$-lobes of the remaining lateral MB subunits are fused in the midline of the brain. Bar $=200 \mu \mathrm{m}$.

In summary, Table 1 indicates that with the moderate HU treatment used (low HU concentration, short treatment duration) the majority of animals exhibited no MB ablations $(52.56 \%)$ or partial unilateral MB ablation (32.87\%). Less frequently, partial bilateral MB ablation was observed (12.6\%). The 3D reconstruction enabled us to demonstrate the extent of these HU-induced lesions. The reconstructions also made it possible to detect MB ablations that occur very rarely or to perceive structural changes that are less massive, such as the reduction of the $\alpha$ - and $\beta$-lobes [Fig. 3(A)-(C)], the fusion of the $\beta$-lobes [Fig. 3(D)], and the ablation of the central body [Fig. 2(E)].

\section{Optical Imaging}

We optically measured the neural responses to odors in a total of 15 bees. In six animals we found signals in only one AL. There was no relationship between the "silent" side and an ablation caused by HU treatment. Totally missing responses in one AL can be due to damage in the preparation, and is not uncommon in optical imaging experiments. In the remaining nine 
animals signals were present on both sides. Of these, one animal was bilaterally ablated, four were unilaterally ablated, and four had intact MBs. After the calcium imaging experiment, we stained the AL with the membrane-selective dye RH795 to visualize the superficial layer of glomerular structure, i.e., about 35 glomeruli, mostly of the T1 region of the AL (Galizia et al., 1999b). No differences were found when comparing ablated animals and nonablated ones, or the left and the right side of unilaterally ablated animals. All glomeruli were present and their shapes and relative sizes corresponded to those of untreated animals. This allowed us to identify the visible glomeruli based on their morphology. We compared the responses to one odor on one side to the responses between sides. No apparent difference was found, indicating that the missing target area did not affect the spatial pattern of odor responses in ALs on the MB-ablated side. An example of odor responses for a unilaterally ablated animal is given in Figure 4. In this animal the right median MB subunit was ablated. Still, the response patterns did not differ more between sides than within one side. Thus, modifications of olfactory processing by the missing target region either did not occur or were below detection threshold. Within our methodologic scope, we can thus be confident that side-specific deficits at the level of olfactory learning and memory, if any, can be ascribed to the partial absence of MB subunits.

\section{Olfactory Conditioning}

Effect of Hydroxyurea Treatment. We first studied the effect of HU treatment per se on olfactory acquisition and retention by comparing the performance of control bees (control: $n=118$ ) and HU-treated bees without MB ablations (HU normal: $n=149$ ). Figure 5 shows the performance of both groups during the four-trial acquisition [Fig. 5(A) and (B)] and the two retention tests [Fig. 5(B) and (C)].

Both groups learned to discriminatively respond to the CS+ but not to the CS - [control: $F(1,234)$ $=10.14, p<.002$; HU normal: $F(1,296)=18.90, p$ $<$.001] and therefore showed a significant variation in their performance during trials [control: $F(3,702)$ $=9.67, p<.001$; HU normal: $F(3,888)=16.80, p$ $<$.001] In both groups the interaction was significant as both control and HU-normal bees increased their response to the $\mathrm{CS}+$ while they diminished their response to the $\mathrm{CS}-$ [control: $F(3,702)=37.91, p$ $<.001$; HU normal: $F(3,888)=27.08, p<.001]$. Nevertheless, differences in responsiveness appeared when comparing both groups. Control bees responded more to the $\mathrm{CS}+$ than HU-normal bees $[F(1,265)$
$=6.37, p<.02]$. This was particularly visible at the end of conditioning (third and fourth CS + trials: both $p<.05)$. In the same way, control bees responded more to the $\mathrm{CS}-$ than HU-normal bees, thus showing fewer differences between response levels to the rewarded versus non-rewarded odor $[F(1,265)=9.70$, $p<.003]$. Differences in responsiveness to the CSwere evident at the beginning of conditioning (first and second $\mathrm{CS}-$ trials: both $p<.05$ ) and disappeared in the last two $\mathrm{CS}-$ trials. Despite the difference between both groups of bees in the general level of responsiveness, both reached the same amount of discriminative performance at the end of conditioning. This can be evaluated by computing a score indexing the number of responses to the $\mathrm{CS}+$ minus those to the $\mathrm{CS}-$ in the last $\mathrm{CS}+$ and $\mathrm{CS}-$ trial, respectively. There were no significant differences in this index between the control and the HU-normal bees $[F(1,265)=1.31$, NS]. Thus, both groups learned equally well to respond to the $\mathrm{CS}+$ but not the $\mathrm{CS}-$; they only differed in their general level of responses [see fourth trial in Fig. 5(A) and (B)].

Similar considerations apply to the retention tests performed 1 and $24 \mathrm{~h}$ after the last acquisition trial [Fig. 5(C) and (D)]. Both groups retained the memories established along the two retention tests and discriminatively responded to the $\mathrm{CS}+$ but not to the $\mathrm{CS}-$ [control: $F(1,232)=81.55, p<.001 ; \mathrm{HU}$ normal: $F(1,290)=65.30, p<.001]$. There was a small albeit significant decrease in responsiveness from the first to the second retention test [control: $F(1,232)=5.53, p<0.02$; HU normal: $F(1,290)$ $=7.54, p<.01]$. The interaction was not significant for both groups of bees [control: $F(1,232)=0.03$, NS; HU normal: $F(1,296)=2.18$, NS]. Again, differences in responsiveness appeared when comparing both groups. Control bees responded more to the $\mathrm{CS}+$ $[F(1,261)=10.13, p<.002]$ and to the CS$[F(1,261)=6.60, p<.02]$ than HU-normal bees. There were no significant differences in the amount of discriminative responding between the control and the HU-normal bees in the first test $[F(1,265)=2.55$, NS]. In the second and last test; however, control bees showed greater differences between response levels to $\mathrm{CS}+$ versus $\mathrm{CS}-[F(1,265)=6.67, p<.02]$ due to the significant decay in $\mathrm{CS}+$ responsiveness in the HU-normal group.

Altogether these results show that HU treatment per se had a general depressing effect on the bees' responsiveness but did not impair their capabilities to respond discriminatively to rewarded but not to nonrewarded odorants. This result will be discussed extensively below. 


\section{Right AL, MB ablated Left AL, MB intact}

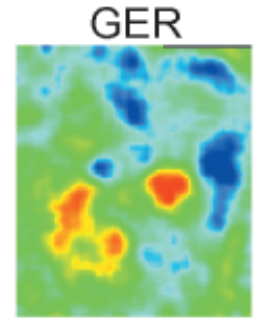

$\mathrm{HX} 1$
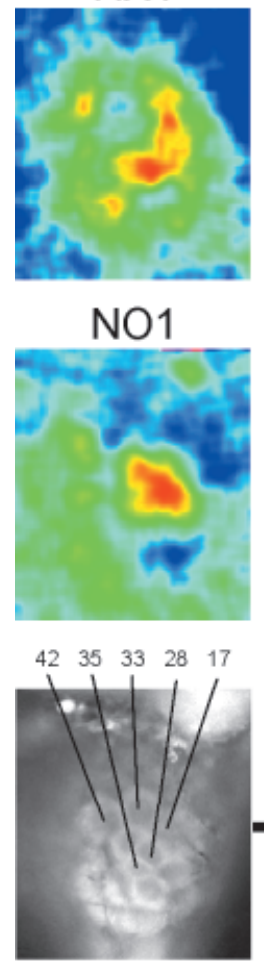

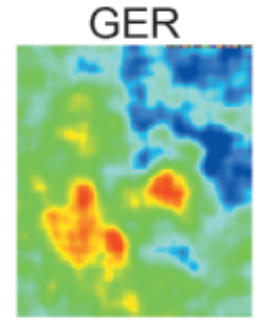

HX1

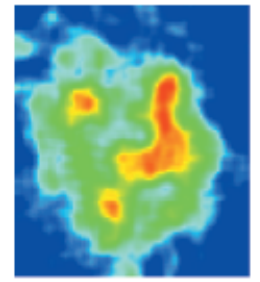

NO1

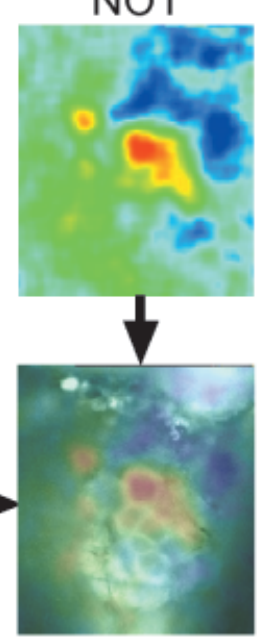

$\min$

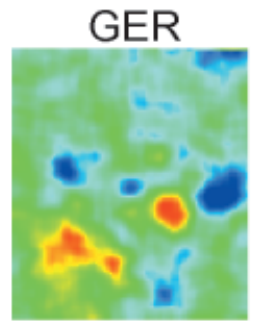

$\mathrm{HX} 1$

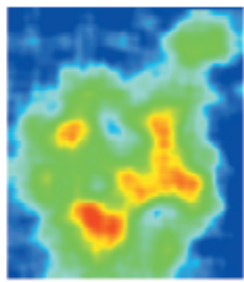

NO1

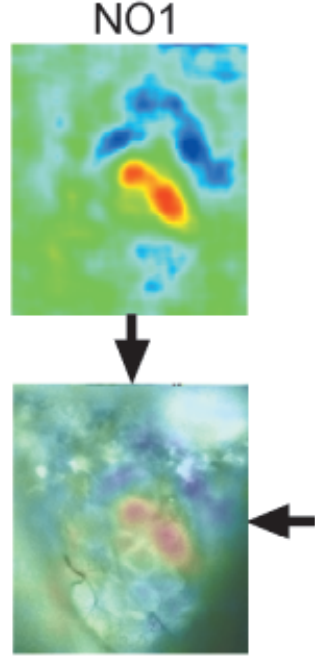

$\max$

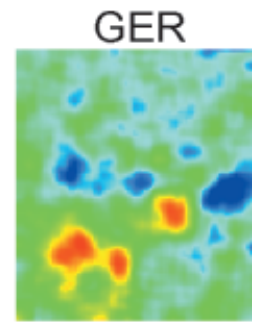

$\mathrm{HX} 1$

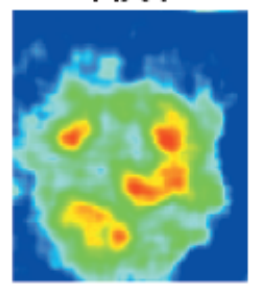

NO1

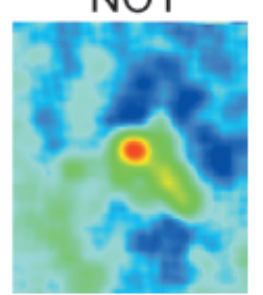

$\begin{array}{lllll}42 & 35 & 33 & 28 & 17\end{array}$

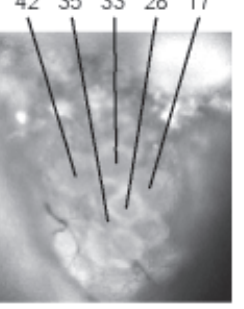

Figure 4 Odor responses in the right and left $\mathrm{AL}$ of a unilaterally MB-ablated animal (right AL, MB ablated; left AL, MB intact). Increases in intracellular calcium are shown as false-color images, red indicating a strong increase, blue-magenta no increase. Each image is scaled to its own maximum to exploit the entire false-color range. Two responses to the three odors geraniol (GER), hexanol (HX1), and 1-nonanol (NO1) are shown for each side. All images of the right AL are mirror-imaged to ease comparison. The antennal nerve points down, lateral is right, medial left. The bottom row shows the glomerular structure as revealed by afterstaining with RH795. In these images the identity of five glomeruli (all from the T1 region of the AL) are given as an example. In the center, the response to nonanol and the afterstaining are superimposed, showing the correspondence between the activity spots and individual glomeruli, which in the case of nonanol are glomeruli 17 and 33. The variability between the spatial odor patterns is not discernible from the variability between sides, indicating that the missing MB does not affect the spatial patterns.

\section{No Effect of Mushroom Body Lesions}

We compared the performances of four groups: HUnormal, HU-ipsilateral (HU-treated animals lacking one median MB subunit on the conditioned antenna side ), HU-contralateral (HU-treated animals with one median MB subunit missing on the side contralateral to the conditioned antenna) and HU-bilateral (HUtreated animals lacking both median MB subunits). All four groups received HU treatment. The HU- 


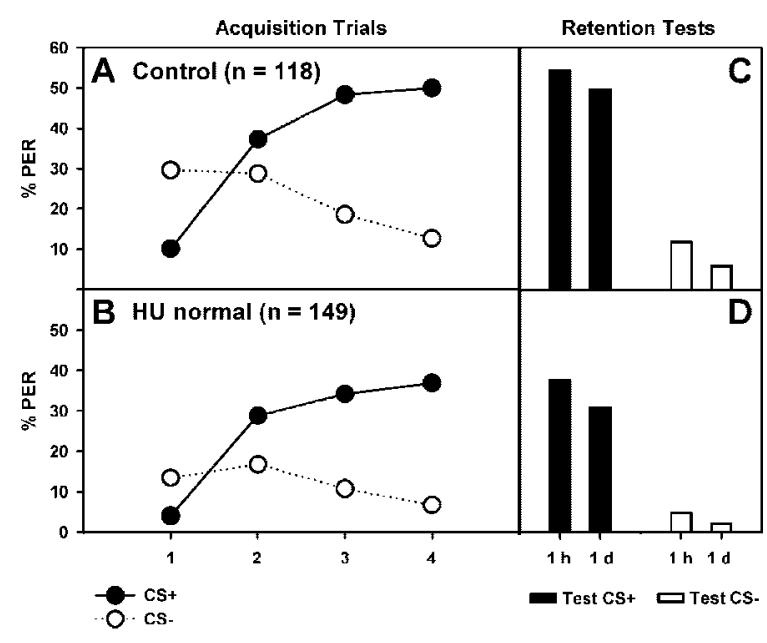

Figure 5 Discriminative olfactory conditioning of the proboscis extension reflex (PER) in control and HU normal bees. One odor (conditioned stimulus, $\mathrm{CS}+$, filled circles) is paired with sucrose (unconditioned stimulus, US) while another odor (CS-, open circles) is not followed by US. Conditioning consisted of four $\mathrm{CS}+$ and four $\mathrm{CS}-$ trials in pseudorandom sequence. (A, B) Acquisition of control animals (A) and HUtreated animals without MB ablation (HU-normal, (B). Both groups learn to discriminatively respond to the $\mathrm{CS}+$ but not to the CS - [control: $F(1,234)=10.14, p<.002$; HU normal: $F(1,296)=18.90, p<.001]$ and show a significant variation in their performance during trials [control: $F(3,702)=9.67, p$ $<.001$; HU normal: $F(3,888)=16.80, p<.001]$. In both groups the interaction is significant as both control and HUnormal bees increase their response to the $\mathrm{CS}+$ while they diminish their response to the $\mathrm{CS}-$ [control: $F(3,702)$ $=37.91, p<.001$; HU normal: $F(3,888)=27.08, p<.001]$. Control bees respond more to the $\mathrm{CS}+$ than HU-normal bees $[F(1,265)=6.37, p<.02]$, particularly at the end of conditioning (third and fourth CS + trials: both $p<.05$ ). Control bees also respond more to the CS - than HU-normal bees $[F(1,265)=9.70, p<.003]$. Differences in responsiveness to the $\mathrm{CS}-$ are evident at the beginning of conditioning (first and second CS - trials: both $p<.05$ ) and disappear in the last two $\mathrm{CS}-$ trials. Both groups reach the same amount of discriminative performance at the end of conditioning $[F(1,265)$ $=1.31, \mathrm{NS}] .(\mathrm{C}, \mathrm{D})$ Retention test of control animals and of HU-normal bees. Both experimental groups respond to the $\mathrm{CS}+$ (filled columns) but not to the $\mathrm{CS}-$ (open columns) [control: $F(1,232)=81.55, p<.001$; HU normal: $F(1,290)$ $=65.30, p<.001]$. The interaction is not significant for both groups of bees [control: $F(1,232)=0.03$, NS; HU normal: $F(1,296)=2.18, \mathrm{NS}]$. Differences in responsiveness appear when comparing both groups. Control bees respond more to the CS $+[F(1,261)=10.13, p<.002]$ and to the CS$[F(1,261)=6.60, p<.02]$ than HU-normal bees. There are no significant differences in the amount of discriminative responding between the control and the HU-normal bees in the first test $[F(1,265)=2.55$, NS]. In the second test control bees show greater differences between response levels to CS+ vs. $\mathrm{CS}-[F(1,265)=6.67, p<.02]$ due to the significant decay in $\mathrm{CS}+$ responsiveness in the HU-normal group. normal group was the reference regarding the question of an MB lesion effect.

As it was not possible to control for the specific kind of lesion generated by the HU treatment, the number of animals differed among groups. To avoid spurious significance due to large differences in sample size, we used groups of the same size $(n=25$ bees). If more animals were available within a group, a random number generator was used to determine the 25 bees used for the analysis. The HU-normal bees used in this analysis did not differ from the previous group of HU-normal bees $[F(1,338)=0.38, \mathrm{NS}]$ and were therefore a representative group for this treatment.

Figure 6 shows the performance of the four groups of bees during the four-trial acquisition [Fig. 6(A)(D)] and the two retention tests [Fig. 6(E)-(H)]. All four groups responded similarly to the $\mathrm{CS}+[F(3,96)$ $=0.95, \mathrm{NS}]$ : they increased their response to the rewarded stimulus during the four conditioning trials $[F(3,288)=19.51, p<.001]$. The interaction was not significant $[F(9,288)=0.53, \mathrm{NS}]$, thus showing that all four CS + curves had the same dynamic variation during trials. Similarly, all four groups did not differ in their response to the $\mathrm{CS}-[F(3,96)=2.30, \mathrm{NS}]$. However, contrarily to the $\mathrm{CS}+$, there were no significant differences in the response to the nonrewarded stimulus during the four conditioning trials $[F(3,288)=0.71, \mathrm{NS}]$. This was due to the fact that the response to the $\mathrm{CS}-$ was low during the entire acquisition phase. The interaction was not significant $[F(9,288)=0.93$, NS $]$. There were no significant differences between groups in the amount of discriminative response reached at the end of acquisition $[F(3,96)=0.58, \mathrm{NS}]$. Thus, all four groups learned to respond discriminatively to the rewarded but not the nonrewarded odor in a similar way.

Finally, we analyzed whether the four groups of bees differed with respect to retention. There were no significant differences between the four groups in their response to the $\mathrm{CS}+$ along the two retention tests $[F(3,92)=0.58$, NS]. A significant decay in $\mathrm{CS}+$ responsiveness was found along the two retention tests $[F(1,92)=9.79, p<.003]$. The interaction was not significant $[F(3,92)=0.20, \mathrm{NS}]$, thus showing that all four groups showed the same pattern of responses to the $\mathrm{CS}+$. The response to the $\mathrm{CS}-$ was the same in all four groups $[F(3,92)=0.43, \mathrm{NS}]$ and remained constant along the two retention tests $[F(1,92)=0.004, \mathrm{NS}]$. The interaction was not significant $[F(3,92)=1.40, \mathrm{NS}]$, thus showing that all four groups showed the same pattern of responses to the CS-. There were no significant differences in the amount of discriminative response between the four 


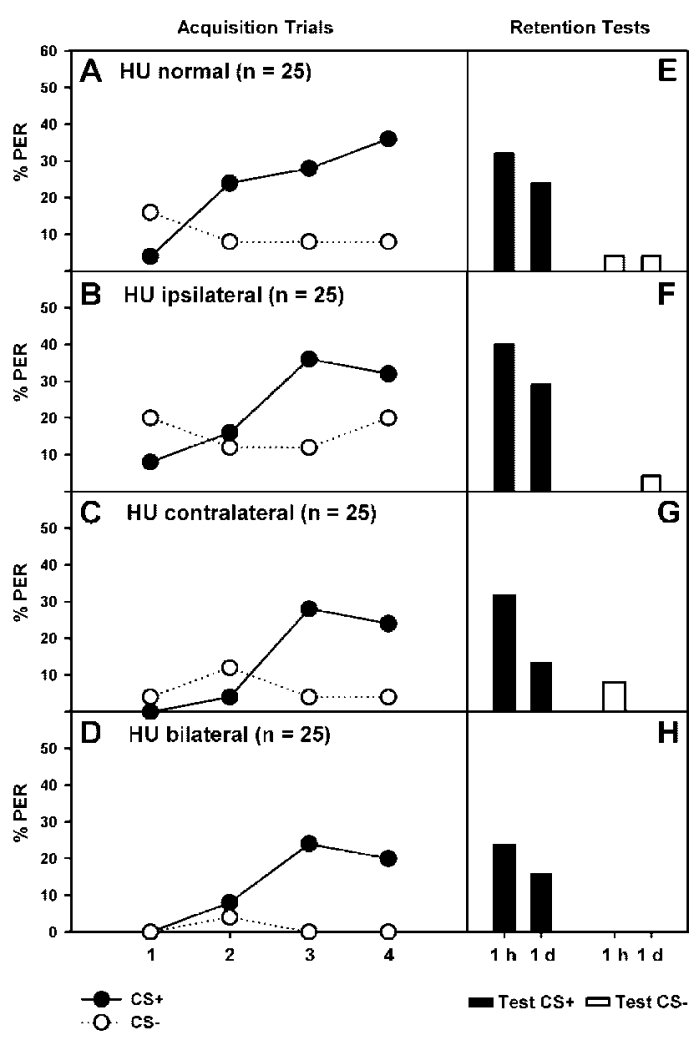

Figure 6 Discriminative olfactory conditioning in HUtreated bees without $\mathrm{MB}$ lesion and bees exhibiting partial MB lesions. Each group consists of 25 bees. (A-D) Acquisition. All four groups respond similarly to the CS+[filled circles; $F(3,96)=0.95, \mathrm{NS}]$ : they increase their response to the rewarded stimulus during the four conditioning trials $[F(3,288)=19.51, p<.001]$. The interaction is not significant $[F(9,288)=0.53, \mathrm{NS}]$. Similarly, all four groups do not differ in their response to the CS- (open circles; $F(3,96)=2.30, \mathrm{NS}]$. There are no significant differences in the response to the nonrewarded stimulus during the four conditioning trials $[F(3,288)=0.71, \mathrm{NS}]$. This is due to the fact that the response to the $\mathrm{CS}-$ is low during the entire acquisition phase. The interaction is not significant $[F(9,288)=0.93, \mathrm{NS}]$. There are no significant differences between groups in the amount of discriminative response reached at the end of acquisition $[F(3,96)=0.58$, NS $]$. Thus, all four groups learn to respond discriminatively to the rewarded but not the nonrewarded odor in a similar way. (E-H) Retention tests. All experimental groups respond more to the $\mathrm{CS}+$ (filled columns) than to the $\mathrm{CS}-$ (open columns). There are no significant differences between the four groups in their response to the CS + along the two retention tests $[F(3,92)=0.58, \mathrm{NS}]$. The interaction is not significant $[F(3,92)=0.20$, NS $]$, thus showing that all four groups show the same pattern of responses to the $\mathrm{CS}+$. The response to the $\mathrm{CS}-$ is the same in all four groups $[F(3,92)$ $=0.43$, NS $]$. The interaction is not significant $[F(3,92)$ $=1.40, \mathrm{NS}]$, thus showing that all four groups show the same pattern of responses to the $\mathrm{CS}-$. There are no significant differences in the amount of discriminative response groups: neither in the first $[F(3,96)=0.69, \mathrm{NS}]$ nor in the second test $[F(3,96)=0.43$, NS $]$.

Thus, the four HU groups showed the same response pattern, both in the acquisition and in the retention tests. The kind of MB lesion did not affect the learning of the differential olfactory conditioning task. All four groups learned to respond to the CS+ and not to the CS - and responded therefore more to the $\mathrm{CS}+$ than to the $\mathrm{CS}-$ in the two retention tests.

\section{DISCUSSION}

The present work shows that adult honeybees with partial HU-induced MB ablations were capable of learning and remembering an elemental olfactory conditioning task. No differences were seen, either in acquisition or in retention, in bees with versus bees without partial MB lesions; furthermore, in unilaterally-ablated animals performance did not depend on the MB status of the side used for conditioning. Thus, MB integrity appears to not be a prerequisite for acquiring a simple olfactory task in which two stimuli are unambiguously associated with reinforcement or the lack of it. Because HU treatment typically results in partial elimination of the MB, two likely explanations come to mind: one is that learning and retention was still possible because of the remaining MB structures. The other one is that MBs are not required for the elemental task under investigation. Before returning to this point, we will first discuss our anatomical and physiologic findings as the basis for our discussion of behavior.

\section{D Reconstructions Clearly Define Mushroom Body Ablations}

The cytostatic drug hydroxyurea (HU) fed to early first-instar honeybee larvae causes the selective ablation of MB subunits (Malun, 1998). In previous studies, HU-induced effects in the brain were demonstrated using five different approaches: (1) immunostaining for PKA (proteinkinase A RII) was performed on brain sections to detect MB ablations (Malun, 1998). This was possible because PKA is predominantly located in the MB neuropil (Müller, 1997). (2) Antibodies against synapsin, which label

between the four groups: neither in the first $[F(3,96)=0.69$, NS $]$ nor in the second test $[F(3,96)=0.43$, NS $]$. Thus, MB lesions do not affect learning and remembering the differential olfactory conditioning task. 
all neuropil areas, were used in whole-mount preparations and also made HU-induced morphological changes in the brain visible (Scheiner et al., 2001, this study). (3) Volumetric measurements on histological sections revealed that the MBs were the only region of the brain affected by $\mathrm{HU}$ in brains with partial MB ablation (Malun et al., 2002). (4) An altered arborization pattern of uniglomerular olfactory projection neurons was found as a consequence of $\mathrm{MB}$ ablation. These neurons, which innervate the lip subdivision of both the lateral and the median MB calyx, lack axon collaterals to the region normally occupied by the median MB calyx in brains with unilateral MB ablation (Malun et al., 2002). (5) Finally, HU treatment not only causes morphologic changes but also alters the amounts of certain proteins that are known to be involved in synaptic plasticity (PKC, PKA, synapsin; Malun et al., 2002).

Here we show that computer-generated reconstructions of stacks of optical sections with immunostained tissue are useful for visualizing HU-induced lesions of the honeybee MBs. These reconstructions enabled us to inspect the honeybee brain as a three-dimensional surface model from different angles. The reconstructions can also be presented in different ways, depending on the purpose of the study. On one hand, various brain areas can be combined to give an overview of the complete brain, as shown in Figures 1 and 2. This allows the observation of the altered MB structure embedded within the rest of the brain, which is not affected by the HU treatment. On the other hand, it is possible to show exclusively the neuropil regions of interest (e.g., the MBs, Fig. 3) without the rest of the brain. This type of presentation mainly emphasizes alterations of the MB structure itself.

The following HU-mediated structural changes have been observed with $3 \mathrm{D}$ reconstructions: most often one or both median MB subunits are ablated, while the lateral MB subunits remain intact. This was also suspected from the examination of brains in which not the entire median subunit was ablated but a severely reduced median MB subunit was left (Malun et al., 2002). The volume of the remaining lateral calyx in the ablated brain side has increased. The $\alpha$ and $\beta$-lobes are reduced when the respective $\alpha$ - and $\beta$-lobe parts of median MB subunits are ablated. Finally, the 3D models convincingly show the fusion of the $\beta$-lobes [Fig. 3(D)] that occurs in some brains with bilateral MB ablation. Thus, the brain reconstructions confirm findings from previous studies (Malun, 1998; Scheiner et al., 2001; Malun et al., 2002) but also improve our knowledge of HU-mediated structural effects in the bee brain.

In the present study, we applied the $3 \mathrm{D}$ technique to brains with characteristic MB ablations (partial unilateral and partial bilateral MB ablation) and brains with ablations that rarely occur (complete MB ablation), and verified its usefulness for qualitative neuropil inspections. The goal of future studies will be to apply this technique to a large number of animals to perform quantitative analyses of HU-induced changes in size, shape, and position of certain brain regions.

\section{Mushroom Body Lesions Do Not Affect Olfactory Processing in the Antennal Lobes}

Using an in vivo calcium-imaging approach with a bath-applied dye $\left(\mathrm{Ca}^{2+}\right.$ green) we showed that olfactory physiology in the ALs is not affected by the absence of the MBs: responses to odors are bilaterally symmetrical in animals with unilaterally ablated MBs. This correlates to results from untreated animals, which also have bilaterally symmetrical odor representations (Galizia et al., 1998). Furthermore, we found that the glomeruli involved in response patterns in animals with unilateral MB lesions are qualitatively the same as those involved in untreated animals (Galizia et al., 1999b; Sachse et al., 1999). For example, for nonanol, glomeruli T1-17 and T1-33 were the most active (Fig. 4), a response pattern that corresponds to that found in untreated animals; similarly, the responses obtained for geraniol and hexanol corresponded to those measured in intact animals (Sachse et al., 1999). Therefore, HU application per se did not seem to lead to obvious distortions in olfactory physiology within the AL. This could represent a blueprint for the functional response patterns of olfactory glomeruli, which is independent of a functional connection to the MBs. However, it is unclear whether olfactory projection neurons function normally within the $\mathrm{AL}$ if the MBs, one of their target areas, are missing. This is because the optical signal measured with our approach is dominated by presynaptic components in the glomeruli (chemoreceptor afferents, local interneurons), and may not reflect the contributions of postsynaptic elements (mainly projection neurons). It therefore cannot be excluded that altered responses of projection neurons and reduced or missing signals from neurons projecting back from the MB to the AL (e.g., the AL-1 neuron; Rybak and Menzel, 1993), may change AL activity patterns. To answer this question it would be necessary to record electrophysiologically from individual projection neurons and to label them for optophysiologic and anatomic studies. Similarly, any changes to the physiologic properties of local interneurons have to be investigated by single-cell electrophysiology. We assume 
that the morphology of the large group of local interneurons is not affected by HU, because a loss of this neuron type (as was observed in HU-treated Drosophila by Stocker et al., 1997) would probably have been detected by our previous volumetric analysis (Malun et al., 2002).

Concerning learning and the AL, Faber et al. (1999) used an elemental olfactory conditioning paradigm (one odor was unambiguously associated with a reinforcement and another one with the lack of it) associated with optical imaging of the AL and showed learning-dependent changes in response intensity of the olfactory glomeruli. Such changes reflect the trace of an odor memory at the AL level. Other experiments based also on elemental olfactory conditioning have shown that the AL is capable of building an olfactory memory trace for itself. Hammer and Menzel (1998) substituted the US (sucrose reward) by local and unilateral AL injections of the putative transmitter (octopamine) of the reward pathway, and found this sufficient to establish an olfactory memory. Injections into a single MB calyx were, albeit with a characteristically different time course, also sufficient to induce memory; injections into the lateral protocerebrum or the optic lobes were without effect. These findings argue that ALs and/ or MBs are candidate structures as loci of associations between odor and reinforcement.

\section{Olfactory Discrimination Unaffected by Partial Mushroom Body Lesions}

Our results show that partial MB ablations did not affect acquisition and retention of side-specific olfactory differential conditioning. In Drosophila a correlation was found between the amount of remaining MB tissue and the accuracy of olfactory learning (deBelle and Heisenberg, 1994). The fact that our results did not show such a correlation can indicate either that the overall smaller lesions obtained in our study might be insufficient to affect olfactory learning and memory as they allowed for developmental compensation, or that MBs are not required in our learning paradigm.

Let us first consider the first possibility, i.e., that the partial lesions induced in our work are insufficient to affect olfactory learning and memory. Experiments using selective cooling of either structure after olfactory conditioning of the proboscis extension reflex have shown that they both are necessary for olfactory associative memory (for review, see Menzel, 1999, 2001). The locally restricted cold pulses applied at different times after a single-learning trial lead to retrograde amnesia with temporal gradients dependent on the structure cooled (Menzel et al., 1974; Erber et al., 1980). Concerning sufficiency, it was mentioned above that the study of Hammer and Menzel (1998) revealed that pairing olfactory stimulation with octopamine injections either into a single AL or a single calyx can be sufficient to support olfactory memory. Thus, the olfactory acquisition and retention found in our work could be supported either by the residual calyces or by the ALs. On the basis of our results we cannot discriminate between these two possibilities. In any event, both interpretations are consistent with the cooling and octopamine injection studies cited above. Finally, the possibility remains that both structures are involved in our case, a scenario equally compatible with all the available data, in particular also with imaging studies, which showed learningdependent increases in $\mathrm{Ca}^{2+}$ signals both in the ALs (Faber et al., 1999) and in the MBs (Mauelshagen, 1993; Faber and Menzel, 2001).

We would like to discuss now the alternative interpretation, i.e., the possibility that the MBs are not involved at all in the learning task under investigation. Our task is an elemental discrimination in the sense that the two CS were unambiguously associated with reinforcement or the lack of it. Such a problem can be solved on the basis of elemental associations between CS and US (Rescorla and Wagner, 1972). Such associations, however, cannot explain solving learning tasks in which ambiguity is raised at the CS level (configural problems; Rudy and Sutherland, 1992; Pearce, 1994). In such problems each CS appears reinforced and nonreinforced, and the only solution to this kind of discrimination is learning each CS in relation to either other CSs or the context. One might thus suggest that MBs may in particular be involved in context-dependent tasks, as suggested by Liu et al. (1999) for context generalization in Drosophila. Using olfactory compounds and single odorants it was shown that bees can indeed solve such kinds of nonelemental tasks (Deisig et al., 2001, 2002). Solving such tasks could depend on the MBs as a neural substrate while elemental, simple learning tasks could be solved already at the level of the ALs. In that regard it is worth underscoring that bees of the ipsilateral group, with a unilateral lesion on the conditioned antenna side, showed the same acquisition and retention as the bees in the contralateral group, with a unilateral lesion on the side opposite the conditioned antenna. If one assumes that the olfactory discrimination trained in our work can be achieved at the level of the AL, this result can be easily explained. Similarly, the elemental nature of the tactile antennal learning task employed by Scheiner et al. (2001) 
might explain that also in that study HU-ablated bees behaved normal.

Taken together, we can safely conclude that MB integrity is not necessary for olfactory learning, at the least not for elemental versions of olfactory discrimination tasks. Whether in partially MB-lesioned animals the ALs or the remaining MBs or both jointly support elemental olfactory acquisition and retention must for the moment remain unanswered.

\section{Mushroom Body-Independent Effects of $\mathrm{HU}$}

HU-treatment had a general detrimental effect on bees' responsiveness. Such a decrease was evident not only in MB-ablated bees but also in HU-treated, nonablated bees. A similar effect was previously observed for tactile antennal learning (Scheiner et al., 2001). We do not know the reasons for such a decrease in responsiveness. Careful volumetric measurements did not point to any specific brain region (Malun et al., 2002); also, an effect in the ALs seems unlikely, as the overall patterns observed in our imaging data much resemble the published patterns for untreated animals. Clearly, subtle effects on single or few cells would not have been picked up by these methods.

Another possibility is that HU might have a general toxic effect on the bee's fitness and viability. Regardless of these considerations, to detect MBspecific learning deficits in future approaches it will be inevitable to compare (as we did in this study) results from $\mathrm{MB}$-ablated bees to results obtained from HU-treated bees without MB lesions.

\section{Comparison to the Mushroom Body Function in Drosophila}

In Drosophila, various approaches indicate that the MBs are needed for olfactory discrimination learning. Mutants in which the MB structure was altered $(M B$ deranged, $m b d$, and $M B$ miniature, $m b m$; Heisenberg et al., 1985) as well as flies in which MBs were chemically ablated via HU treatment (deBelle and Heisenberg, 1994) exhibit deficits in olfactory learning. Also, olfactory discrimination learning was disrupted in transgenic flies in which a constitutively active G-protein subunit was expressed in the MBs, thus potentially leading to a reduced ability to modulate G-protein signaling (Connolly et al., 1996). Recently, Pascual and Préat (2001), confirmed these findings for longer term memory using alpha-lobes absent (ala) mutants. Together, these studies suggested a necessary role of the MBs for olfactory learning, a conclusion in line with the situation in the honeybee. Concerning sufficiency, the olfactory learning defect observed in animals mutant in the type 1 adenylate cyclase (rut-), and therefore likely impaired in synaptic plasticity, can be restored when expression of the wildtype cyclase is allowed in the MBs (Zars et al., 2001); this result argues that plasticity within the MBs is sufficient for olfactory memory. Concerning sufficiency in honeybees, this is in line with the data provided by Hammer and Menzel (1998) on octopamine injections in the MBs as discussed above. Recently, and also corresponding to these interpretations, McGuire and colleagues (2001) as well as Dubnau et al. (2001) used a transient, temperature-dependent inactivation method through the shibire-ts gene product and showed that MB output is not needed for acquisition, but is needed for retention of olfactory memories. A similar conclusion was reached by Lozano et al. (2001) for honeybees. Results from these various approaches in Drosophila and the honeybee confirm that the MBs are involved in acquisition, storage, and retrieval of olfactory memory. To investigate whether different parts of the MBs might contribute differentially to these processes is currently a hot area of research, also with respect to the question of common functional design in honeybees and flies.

In any event, genetic manipulations are not yet feasible in the honeybee. Nevertheless, using the chemical ablation method we will now proceed to address more specific questions. In particular, one should continue the side-specific olfactory conditioning experiments. Such an approach, which has not yet been attempted in Drosophila was recently established by Sandoz and Menzel (2001). From these experiments, which leave both antenna intact, but which physically separate the input sides, we can potentially further our understanding of the contribution of MB subunits to olfactory learning and memory and their interaction between brain sides. In another set of experiments one could address the question of whether honeybees with MB lesions are able to process configural associations such as negative and positive patterning discrimination problems, as was recently studied with intact honeybees by Deisig et al. (2001, 2002).

We thank Ariane Moseleit for help with the 3D reconstructions, and Nicola Stollhoff for generously providing Figure 1. We are grateful to Maaike Binner, Sven Enders, and Arnim Jenett for their help with behavioral experiments. We thank Erich Buchner (Würzburg, Germany), and Alois Hofbauer (Regensburg, Germany) for generously providing the antisera against synapsin. We particularly thank Bernhard Komischke, Randolf Menzel, Uli Müller, and Jean 
Christoph Sandoz for their helpful comments and suggestions. We also thank Mary Wurm for linguistic corrections.

\section{REFERENCES}

Abel R, Rybak J, Menzel R. 2001. Structure and response pattern of olfactory interneurons in the honeybee, Apis mellifera. J Comp Neurol 437:363-383.

Anagnostaras SG, Maren S, Fanselow MS. 1999. Temporally graded retrograde amnesia of contextual fear after hippocampal damage in rats: within-subjects examination. J Neurosci 19:1106-1114.

Bitterman ME, Menzel R, Fietz A, Schäfer S. 1983. Classical conditioning of proboscis extension in honeybees (Apis mellifera). J Comp Psychol 97:107-119.

Bucher D, Scholz M, Stetter M, Obermayer K, Pflüger H-J. 2000. Correction methods for three-dimensional reconstructions from confocal images: I. tissue shrinking and axial scaling. J Neurosci Methods 100:135-143.

Connolly JB, Roberts IJH, Armstrong JD, Kaiser K, Forte M, Tully T, O'Kane CJ. 1996. Associative learning disrupted by impaired $\mathrm{G}_{\mathrm{s}}$ signalling in Drosophila mushroom bodies. Science 274:2104-2107.

Davis RL. 1996. Physiology and biochemistry of Drosophila learning mutants. Physiol Rev 76:299-317.

deBelle JS, Heisenberg M. 1994. Associative odor learning in Drosophila abolished by chemical ablation of mushroom bodies. Science 263:692-695.

Deisig N, Lachnit H, Giurfa M. 2002. The effect of similarity between elemental stimuli and compounds in olfactory patterning discriminations by honeybees. Learn Mem 9:112-121.

Deisig N, Lachnit H, Giurfa M, Hellstern F. 2001. Configural olfactory learning in honeybees: negative and positive patterning discrimination. Learn Mem 8:70-78.

Dubnau J, Grady L, Kitomoto T, Tully T. 2001. Disruption of neurotransmission in Drosophila mushroom body blocks retrieval but not acquisition of memory. Nature 411:476-480.

Dubnau J, Tully T. 2001. Functional anatomy: from molecule to memory. Curr Biol 11:R240-R243.

Erber J, Masuhr T, Menzel R. 1980. Localization of shortterm memory in the brain of the bee, Apis mellifera. Physiol Entomol 5:343-358.

Faber T, Menzel R. 2001. Visualizing mushroom body response to a conditioned odor in honeybee. Naturwissenschaften 88:472-476.

Faber T, Joerges J, Menzel R. 1999. Associative learning modifies neural representations of odors in the insect brain. Nat Neurosci 2:74-78.

Farris SM, Robinson GE, Davis RL, Fahrbach SE. 1999. Larval and pupal development of the mushroom bodies in the honeybee, Apis mellifera. J Comp Neurol 414:97-113.

Galizia CG, McIlwrath SL, Menzel R. 1999a. A digital three-dimensional atlas of the honeybee antennal lobe based on optical sections acquired using confocal microscopy. Cell Tissue Res 295:383-394.
Galizia CG, Menzel R. 2001. The role of glomeruli in the neural representation of odours: results from optical recording studies. J Insect Physiol 47:115-130.

Galizia CG, Nägler K, Hölldobler B, Menzel R. 1998. Odour coding is bilaterally symmetrical in the antennal lobes of honeybees (Apis mellifera). Eur J Neurosci 10: 2964-2974.

Galizia CG, Sachse S, Mustaparta H. 2000. Calcium responses to pheromones and plant odours in the antennal lobe of the male and female moth Heliothis virescens. J Comp Physiol A 186:1049-1063.

Galizia CG, Sachse S, Rappert A, Menzel R. 1999b. The glomerular code for odor representation is species-specific in the honeybee Apis mellifera. Nat Neurosci 2:473478.

Hammer M. 1997. The neural basis of associative reward learning in honeybees. Trend Neurosci 20:245-252.

Hammer M, Menzel R. 1998. Multiple sites of associative odor learning as revealed by local microinjections of octopamine in honeybees. Learn Mem 5:146-156.

Heisenberg M, Borst A, Wagner S, Byers D. 1985. Drosophila mushroom body mutants are deficient in olfactory learning. J Neurogenet 2:1-30.

Heisenberg M. 1998. What do the mushroom bodies do for the insect brain? An introduction. Learn Mem 5:1-10.

Hofbauer A. 1989. Eine Bibliothek monoklonaler Antikörper gegen das Gehirn von Drosophila melanogaster. Habilitation thesis, University of Würzburg.

Ito K, Awano W, Suzuki K, Hiromi Y, Yamamoto D. 1997. The Drosophila mushroom body is a quadruple structure of clonal units each of which contains a virtually identical set of neurones and glial cells. Development 124:761771.

Joerges J, Küttner A, Galizia C, Menzel R. 1997. Representations of odours and odour mixtures visualized in the honeybee brain. Nature 387:285-288.

Kandel ER, Schwartz JH. 1982. Molecular biology of learning: modulation of transmitter release. Science 218:433443.

Liu L, Wolf R, Ernst R, Heisenberg M. 1999. Context generalization in Drosophila visual learning requires the mushroom bodies. Nature 400:753-756.

Lozano VC, Armengaud C, Gauthier M.J. 2001. Memory impairment induced by cholinergic antagonists injected into the mushroom bodies of the honeybee. J Comp Physiol A 187:249-254.

Lunney GH. 1970. Using analysis of variance with a dichotomous dependent variable: an empirical study. J Educat Meas 7:263-269.

Malun D. 1998. Early development of mushroom bodies in the brain of the honeybee Apis mellifera as revealed by BrdU incorporation and ablation experiments. Learn Mem 5:90-101.

Malun D, Plath N, Moseleit AD, Giurfa M, Müller U. 2002. Hydroxyurea-induced partial mushroom body ablation in the honeybee Apis mellifera: Volumetric analysis and quantitative protein determination. J Neurobiol 50:3144. 
Mauelshagen J. 1993. Neural correlates of olfactory learning in an identified neuron in the honeybee brain. J Neurophysiol 69:609-625.

McGuire SE, Phuang TL, Davis RL. 2001. The role of Drosophila mushroom body signaling in olfactory memory. Science 293:1330-1333.

Menzel R. 1999. Memory dynamics in the honeybee. J Comp Physiol A 185:323-340.

Menzel R. 2001. Searching for the memory trace in a mini-brain, the honeybee. Learn Mem 8:53-62.

Menzel R, Giurfa M. 2001. Cognitive architecture of a mini-brain: the honeybee. Trends Cogn Sci 5:62-71.

Menzel R, Müller U. 1996. Learning and memory in honeybees: from behavior to neural substrates. Annu Rev Neurosci 19:379-404.

Menzel R, Durst CD, Erber J, Eichmüller S, Hammer M, Hildebrand H, Mauelshagen J, Müller U, Rosenboom H, Rybak J, Schäfer S, Scheidler A. 1994. The mushroom bodies in the honeybee: from molecules to behaviour. In: Schildberger K, Elsner N, editors. Fortschritte der Zoologie 39. Neural basis of behavioural adaptations. Stuttgart: Fischer, p 81-102.

Menzel R, Erber J, Masuhr T. 1974. Learning and memory in the honeybee. In: Barton-Browne L, editor. Experimental analysis of insect behavior. Berlin: Springer, $p$ 195-217.

Milner B, Squire LR, Kandel ER. 1998. Cognitive neuroscience and the study of memory. Neuron 20:445-468.

Mobbs PG. 1984. Neural networks in the mushroom bodies of the honeybee. J Insect Physiol 30:43-58.

Müller U. 1997. Neuronal cAMP-dependent protein kinase type II is concentrated in mushroom bodies of Drosophila melanogaster and the honeybee Apis mellifera. J Neurobiol 33:33-44.

Pascual A, Préat T. 2001. Localization of long-term memory within the Drosophila mushroom body. Science 294: 115-117.

Pearce JM. 1994. Similarity and discrimination: a selective review and a connectionist model. Psychol Rev 101:587607.

Rescorla RA, Wagner AR. 1972. A theory of Pavlovian conditioning: variations in the effectiveness of reinforcement and nonreinforcement. In: Black AH, Prokasy WF, editors. Classical conditioning 2: current research and theory. New York: Appleton-Century-Crofts, p 64-99.

Riedel G, Micheau J, Lam AG, Roloff E, Martin SJ, Bridge H, Hoz L, Poeschel B, McCulloch J, Morris RG. 1999.
Reversible neural inactivation reveals hippocampal participation in several memory processes. Nat Neurosci 2:898-905.

Rohlfing T, Brandt R, Maurer CR Jr, Menzel R. 2001 Bee Brains, B-splines and computational democracy: generating an average shape atlas. In Proceedings of IEEE workshop on mathematical methods in biomedical image analysis-MMBIA, Kauai, Hawaii USA. p 187-194.

Rudy JW, Sutherland RJ. 1992. Configural association theory and the hippocampal formation: an appraisal and reconfiguration. Hippocampus 5:375-389.

Rybak J, Menzel R. 1993. Anatomy of the mushroom bodies in the honeybee brain: the neuronal connections of the alpha-lobe. J Comp Neurol 334:444-465.

Rybak J, Menzel R. 1998. Integrative properties of the Pe1 neuron, a unique mushroom body output neuron. Learn Mem 5:133-145.

Sakai N, Yamamoto T. 2001. Effects of excitotoxic brain lesions on taste-mediated odor learning in the rat. Neurobiol Learn Mem 75:128-139.

Sandoz J-C, Menzel R. 2001. Side-specificity of olfactory learning in the honeybee: generalization between odors and sides. Learn Mem 8:286-294.

Sachse S, Rappert A, Galizia CG. 1999. The spatial representation of chemical structures in the antennal lobe of honeybees: steps towards the olfactory code. Eur J Neurosci 11:3970-3982.

Scheiner R, Weiss A, Malun D, Erber J. 2001. Learning in honey bees with brain lesions: how partial mushroombody ablations affect sucrose responsiveness and tactile antennal learning. Anim Cogn 3:227-235.

Sutton MA, Masters SE, Bagnall MW, Carew TJ. 2001. Molecular mechanisms underlying a unique intermediate phase of memory in Aplysia. Neuron 31:143-154.

Takeda K. 1961. Classical conditioned response in they honey bee. J Insect Physiol 6:168-179.

Zars T, Fischer M, Schulz R, Heineberg M. 2001. Localization of a short-term memory in Drosophila. Science 288:672-675.

Zuschratter W, Steffen T, Braun K, Herzog A, Michaelis B, Scheich H. 1998. Acquisition of multiple image stacks with a confocal laser scanning microscope. In: Threedimensional and multidimensional Microscopy: image acquisition and processing $\mathrm{V}$, proceedings of the international society for optical engineering. SPIE 3261:177186. 